\title{
Incentivo à cultura surda nos processos educacionais: experiência visual e desenvolvimento linguístico em foco
}

\begin{abstract}
Resumo: Este artigo analisa práticas pedagógicas de professoras surdas que atuam com alunos(as) surdos(as) em escolas públicas regulares de João Pessoa-PB. Com base nos Estudos Surdos, evidenciamos as produções culturais que emergem de suas experiências visuais, materializadas na língua e identidades surdas. Para tanto, fizemos observações e entrevistas com três professoras surdas que desenvolviam o Atendimento Educacional Especializado, nas Salas de Recursos Multifuncionais, espaço onde consideramos que as interações entre pessoas surdas (docente-discente) ocorriam mais diretamente. Das situações pedagógicas e narrativas das professoras surdas, destacamos elementos, como: a experiência visual e o desenvolvimento linguístico. As análises mostraram que é possível a construção de processos pedagógicos que unam a educação e a cultura surda, desde que os artefatos desta sejam considerados e haja suporte para o adensamento de processos educacionais que empreendam esforço para trazer a diferença para o centro do processo. Esse é o caminho para a escola se tornar, realmente, mais inclusiva.

Palavras-chave: Educação. Educação dos surdos. Educação inclusiva.
\end{abstract}

\section{Introdução}

Esta pesquisa ${ }^{1}$ baseia-se nos Estudos Surdos, entendendo-os, assim como Skliar(2013), como um campo de conhecimentos quebusca trazer para o centro da discussão a forma como as pessoas surdas se reconhecem. O desafio dos Estudos Surdos é problematizar os discursos normalizadores e as práticas padronizadas produzidos sobre as pessoas surdas, evidenciando as produções culturais que emergem de suas experiências visuais, materializadas na língua e identidades/alteridades surdas.

A base epistemológica dos Estudos Surdos surge tendo como referência os Estudos Culturais, que, por problematizar a cultura no campo do discurso e da linguagem, constitui-se uma arena complexa de significados. Conforme Silva (2011, p. 133-134):

A cultura é um campo de produção de significados no qual os diferentes grupos sociais, situados em posições diferenciais de poder, lutam pela imposição de seus significados à sociedade mais ampla. A cultura é, nessa concepção, um campo contestado de significação [...]. A cultura é um campo onde se define não só a forma que o mundo deve ter, mas também a forma como as pessoas e os grupos de vem ser. A cultura é um jogo de poder.
Ana Dorziat

Universidade Federal de Campina Grande (UFCG)

ana_dorziat@hotmail.com Maiane Machado de Morais Universidade Federal da Paraíba (UFPB)

maianelg@yahoo.com.br Luzenice Simey Macedo de Carvalho

Universidade Federal da Paraíba (UFPB)

lumah80@hotmail.com

Lucas Romário

Universidade Federal da Paraíba (UFPB)

Universidade Federal do Cariri (UFCA)

lucas.romario@ufca.edu.br

(1) Pesquisa financiada pelo Conselho Nacional de Desenvolvimento Científico e Tecnológico (CNPq). 
Nessa linha de pensamento, o conceito unificado de cultura é desconstruído. A noção de que há uma cultura (erudita) superior a outras é desmistificada, tomando forma uma noção plural acerca desse conceito. Partindo desse pressuposto, práticas consideradas subculturas passam a ser respeitadas como uma cultura com características e artefatos distintos, originais e autênticos. Esse é o caso da cultura surda.

Embora ainda pouco compreendida devido ao arraigamento do argumento biológico, que considera como padrão de normalidade o ouvir e o oralizar, os estudos vêm, aos poucos, desconstruindo esse argumento hegemônico sobre a condição surda. Para a autora surda Strobel (2013, p. 29):

\footnotetext{
Cultura surda é o jeito de o sujeito surdo entender o mundo e de modificá-lo a fim de torná-lo acessível e habitável, ajustando-o com as suas percepções visuais, que contribuem para a definição das identidades surdas e das 'almas' das comunidades surdas. Isso significa que abrange a língua, as ideias, as crenças, os costumes e os hábitos do povo surdo.
}

Segundo Gesueli (2006, p. 284), a cultura surda - arte, humor, teatro, poesia etc.-nasce "na medida em que os surdos legitimam sua língua e sua comunidade". Esses artefatos culturais que definem o mundo singular das pessoas surdas "[...] não se refere[m] apenas a materialismos culturais, mas àquilo que na cultura constitui produções do sujeito que tem seu próprio modo de ser, ver, entender e transformar o mundo". (STROBEL, 2013, p. 43-44)

Nesse sentido, dizemos que a experiência visual constitui a cultura surda porque é por meio dela que o mundo se aproxima das pessoas surdas e elas se aproximam do mundo. Essa percepção se impõe até para aquelas pessoas surdas que não usam a língua de sinais. O som, elemento constituidor das pessoas ouvintes usuárias da língua oral, é dispensável para elas. (ROMÁRIO; DORZIAT, 2016) Strobel (2013, p. 45) diz que "os sujeitos surdos, com a ausência de audição e do som, percebem o mundo através de seus olhos e de tudo o que ocorre ao redor deles: desde os latidos de um cachorro [...] até de uma bomba estourando [...] ".

O potencial visual presente na cultura surda gerou um importante elemento de constituição humana, responsável pelo desenvolvimento cognitivo, social e afetivo das pessoas surdas: a língua de sinais. Sem a aquisição da linguagem, essas pessoas terão seus 
processos cognitivos e, consequentemente, sua inserção na vida social e escolar limitados. Para Skliar (2013), a língua de sinais é o meio mais eficaz nesse processo de inserção social.

As línguas materializam as capacidades dos seres humanos, expressam as culturas, os valores e os padrões sociais de um determinado grupo social. No caso das pessoas surdas brasileiras, essa língua é a Língua Brasileira de Sinais (Libras), "[...] uma língua viso-espacial que apresenta todas as propriedades específicas das línguas humanas". (QUADROS, 2006, p. 13)

Destarte, sustentamos que, em termos educacionais, quanto mais a cultura surda estiver imbricada nos anos iniciais de escolarização das pessoas surdas, tendo o convívio escolar com adultos(as) surdos(as), usuários(as) da língua de sinais, as crianças surdas poderão ter o seu desenvolvimento potencializado.

Atualmente, mesmo diante de questões a serem problematizadas e, até mesmo, superadas, no que diz respeito à política educacional predominantemente em vigência (inclusão), algumas ações foram implementadas no que diz respeito à educação de pessoas surdas, entre elas, um espaço que proporcionasse um atendimento educacional especializado, com a finalidade de atender as especificidades desses sujeitos.

As recomendações é que as práticas pedagógicas nesse espaço sejam realizadas por diferentes profissionais: um(a) professor(a) de Língua Brasileira de Sinais (Libras), preferencialmente surdo(a), e um(a) de Língua Portuguesa, preferencialmente graduado(a) em Língua Portuguesa. (DAMÁZIO, 2007)

Pensando na configuração desses processos educacionais para alunos(as) surdos(as), desenvolvemos uma pesquisa com o objetivo de analisar as práticas pedagógicas de professores(as) surdos(as) que atuam com alunos(as) surdos(as).

\section{Caminhos metodológicos}

O desenvolvimento dessa pesquisa teve caráter qualitativo, ou seja, "[...] trabalha com o universo de significados, motivos, aspirações, crenças, valores e atitudes, o que corresponde a um espaço mais profundo das relações [...]". (MINAYO, 2001, p. 21-22) Pensamos que assim, os fenômenos educacionais e culturais podem ser analisados de modo crítico e reflexivo, a partir do olhar das pesquisadoras e do pesquisador, face a realidade e a base teórica. 
A primeira ação da pesquisa tratou dos procedimentos éticos, com autorização da Secretaria de Educação do Município e do Comitê de Ética. Após esses procedimentos, foi realizado um mapeamento das escolas de João Pessoa-PB, onde trabalhavam os(as) professores(as) surdos(as). O referido mapeamento fez-nos identificar três professoras surdas que desenvolviam Atendimento Educacional Especializado (AEE) em três diferentes escolas, nas Salas de Recursos Multifuncionais (SRM). Diante dessa realidade, optamos por realizar a pesquisa nesse espaço, onde consideramos que as interações entre pessoas surdas (docente-discente) ocorriam mais diretamente.

As três professoras surdas, sujeitos da pesquisa, foram identificadas com nomes fictícios: Paula, Priscila e Perla.

Como instrumentos de coleta de dados, usamos a observação e a entrevista. Optamos por observações não participantes (RICHARDSON, 1999), por considerarmos ser importante não interferir nas situações pedagógicas. Para registrá-las, utilizamos um diário de campo, no qual anotamos todos os dados relacionados ao objeto de pesquisa. As anotações foram o mais detalhadas possível, seguindo as recomendações de Cruz Neto (2000, p. 64), para quem "quanto mais rico forem feitas as anotações nesse diário, maior será o auxílio que oferecerá à descrição e à análise do objeto estudado".

As observações nas Salas de Recursos Multifuncionais ocorreram nos horários e dias previamente definidos, conforme diálogo com as professoras e montagem de cronograma. Tais momentos foram vivenciados de forma não participativa, porém, em algumas situações, fomos solicitadas pelas docentes a interagir com os(as) discentes. Nestes momentos peculiares, tentamos auxiliá-los(as) sem interferir na metodologia das mesmas, de modo a não enviesar nossos dados.

Quanto às entrevistas, resolvemos construir uma entrevista semiestruturada, por permitir "fazer aprofundamento das visões e das opiniões onde for desejável que os respondentes aprofundem suas respostas". (GRAY, 2012, p. 302) Elas foram realizadas em Libras, gravadas com câmeras digitais e, posteriormente, traduzidas para o português.

Consideramos a entrevista semiestruturada um instrumento adequado para a pesquisa, uma vez que parte de certos questionamentos básicos que interessam à pesquisa e que oferecem um amplo campo de interrogativas. (TRIVIÑOS, 1987) 
Após a coleta, foram realizados os seguintes procedimentos:

a. Ordenação dos dados: transcrevemos no computador todas as anotações feitas durante as observações das práticas pedagógicas de cada professora, além de traduzirmos todas as entrevistas em Libras para a Língua Portuguesa e, depois, transcrevê-las.

b. Categorização dos dados: pensando na análise de conteúdo em uma perspectiva mais qualitativa, híbrida, elencamos categorias para este estudo, que surgiram explicitamente nas observações e nas narrativas das professoras durante as entrevistas.

c. Análise dos dados: nessa fase, articulamos os dados empíricos com os referenciais teóricos dos Estudos Culturais e dos Estudos Surdos e relacionamos as práticas pedagógicas das professoras surdas às narrativas proferidas durante as entrevistas, a fim de desenvolver uma análise, articulando prática e discurso. Para tanto, utilizamos princípios da análise de conteúdo, considerando o significado atribuído por Bardin (2011, p. 15), qual seja: “[...] um conjunto de instrumentos metodológicos cada vez mais sutis em constante aperfeiçoamento, que se aplicam a 'discursos' (conteúdos e continentes) extremamente diversificados". A análise de conteúdo foi incorporada à pesquisa, por permitir que diversos instrumentos e técnicas pudessem ser utilizados no processo investigativo, permitindo uma análise mais sistêmica.

\section{Cultura surda nas práticas pedagógicas}

Nesta seção, apresentamos os resultados da pesquisa, evidenciando situações pedagógicas e narrativas das professoras surdas sobre elementos que ganham destaque, devido à sua importância na educação de pessoas surdas. Os elementos são a experiência visual e o desenvolvimento linguístico.

\subsection{Experiência visual}

Durante uma das observações dos processos educacionais, a professora Priscila sinalizou a importância do uso de recursos visuais, jogos, brincadeiras e metodologias diferenciadas para cada uma de 
suas alunas, visto que cada uma delas apresentava níveis diferentes de aprendizagem. Priscila expôs o livro produzido por ela, denominado Livro sensorial, que possuía atividades interdisciplinares.

\begin{tabular}{|c|}
\hline SITUAÇÃO 1 \\
\hline Professora Priscila \\
\hline $\begin{array}{l}\text { Trabalhando em seu "Livro sensorial", na página onde constavam todas as letras do alfa- } \\
\text { beto e imagens de objetos que representavam cada uma delas, a professora apresentou } \\
\text { uma letra expressa em fichas e solicitou que suas alunas surdas apresentassem a gravu- } \\
\text { ra que iniciasse com a letra que estava em sua mão. Na letra J, uma de suas alunas não } \\
\text { conseguiu encontrar a gravura correspondente para "JOANINHA". A professora passou, } \\
\text { então, a dar dicas para que ela descobrisse e encontrasse a gravura: "tem a cor verme- } \\
\text { lha, é pequenininha"! A outra criança surda, percebendo as dificuldades de sua amiga } \\
\text { em encontrar a imagem da "JOANINHA", mostrou em um painel que estava exposto na } \\
\text { sala a letra e a gravura de "JOANINHA". }\end{array}$ \\
\hline
\end{tabular}

Fonte: Dado colhido pelos/as autores/as.

$\mathrm{Na}$ abordagem, à professora trabalhava imagens que faziam referência à primeira letra de cada gravura. Quando percebeu que uma de suas alunas não estava conseguindo encontrar a gravura que iniciava com a letra J de "JOANINHA", ela indicou o tamanho e a cor da imagem para ajudar a criança.

A interação entre elas, durante a atividade, era evidente. Por meio da Libras, a comunicação professora-aluna se dava de forma fluida. Essa dinâmica foi aprofundada pela produção de material pedagógico visual desenvolvido pela própria professora surda. Ao selecionar um material didático coerente com as percepções das pessoas surdas, a professora parece refletir seu entendimento sobre a importância da experiência visual para as suas vidas: dela e da aluna. Perlin e Miranda (2003, p. 218) sustentam que:

Experiência visual significa a utilização da visão (em substituição total à audição), como meio de comunicação. Desta experiência visual surge a cultura surda representada pela língua de sinais, pelo modo diferente de ser, de se expressar, de conhecer o mundo, de entrar nas artes, no conhecimento científico e acadêmico.

A iniciativa da professora é superadora de muitas práticas consideradas inclusivas na sala de aula. Muitas vezes, essas práticas tomam a Libras como único elemento de inserção dos alunos(as) surdos(as), desconsiderando que a língua é apenas um dos elementos que refletem a cultura surda. Para que, de fato, as pessoas surdas tenham uma educação de qualidade, é necessário que os 
processos educacionais que as envolvem tenham como foco suas singularidades com aspectos que integram seu mundo visual.

Ao produzir o material visual, a professora Priscila apresenta valores da cultura surda, buscando desenvolver processos educacionais realmente inclusivos. Com isso, ela mostra que o respeito e a valorização das diferenças não pode ser um princípio visto pela metade, mas que faça parte de cenário significativo para os sujeitos aos quais se destinam os esforços pedagógicos.

Ademais, a professora surda seguiu as recomendações elencadas na política educacional inclusiva, no tocante ao Atendimento Educacional Especializado (AEE). Ao elaborar tais recomendações para o AEE de pessoas surdas, Damázio (2007, p. 38) enfatiza a importância da "riqueza de materiais e recursos visuais (imagéticos) para possibilitar a abstração dos significados de elementos mórficos da Língua Portuguesa". Ampliamos a recomendação da autora que produziu o material orientador do Ministério da Educação (MEC): deverá haver uma riqueza de materiais e recursos visuais, a fim de que se possibilite a abstração dos significados de elementos da Libras, da Língua Portuguesa na modalidade escrita e de quaisquer outros conteúdos escolares.

Para o desenvolvimento da Libras, da Língua Portuguesa escrita e de quaisquer outros conteúdos, recursos adequados - como são os materiais visuais - são essenciais, pois contribuem significativamente para a aprendizagem das crianças surdas.

Nesse sentido, uma das professoras reclama da ausência de recursos visuais no AEE, ao mesmo tempo em que indica a sua relevância no processo de ensino e aprendizagem:

Faltam vários materiais visuais. Eu utilizo meus próprios materiais. Eu preciso comprar.Você viu o DVD visual para surd@s?²Eu gosto muito.Eu coloco oDVDe explico e, quandoel@snãoentendem,el@s vão perguntando e eu vou explicando. Por exemplo, ele viu o DVD do INES [Instituto Nacional de Educação de Surdos] e perguntou: 'o que é isso?',eu respondi: 'uma escola própria parasurd@s. Ele: 'uma escola?'Ai, quandoel@sveemovídeorm outrodia,el@s lembram: 'Ah! Uma escola de surd@s'. Mas falta explicar a história. Como tempo,el@svão se desenvolvendo,vão entendendo que o INESéprópriopara@surd@s,tem teatrodesurd@s...mas, a históriael@saindanão entendem bem,não.A FUNAD[Fundação Centro Integrado de Apoio ao Portador de Deficiência] é uma escola de acessibilidade, tem intérprete, tem acessibilidade.El@svão para escola e para FUNAD,vão para os dois, por issoqueel@s ainda
(2) Utilizamos @ na tradução/ transcrição das falas das professoras porque em Libras, na cultura surda, as pessoas utilizam o gênero neutro, salvo naqueles casos em que, de fato, necessitase marcar o gênero. 
não entendem. [...] Eu mostro fotos, DVD em Libras com teatro própriod@surd@s.Explicoael@squenãoéaqui,ébem longe, só tem como ir de avião.Éno Rio de Janeiro. Mas el@s sabem que o teatroéda culturasurda.El@s perguntam: 'el@s são ouvintes?'; eu respondo 'Não,sãosurd@sque fazemo teatro'. (Professora Perla).

Apesar da carência de materiais visuais, ela fazia questão de utilizar os poucos que haviam disponíveis na sala de recursos, ensinando, por exemplo, a história das pessoas surdas através de DVD visual. Ela trouxe, por meio do DVD, a história do Instituto Nacional de Educação de Surdos (primeira escola para pessoas surdas no Brasil). Desse modo, Perla também contribui para a construção de identidades das crianças surdas, mostrando os processos históricos pelos quais passaram os seus pares culturais e que favoreceram um reconhecimento social e identitário da população surda.

O desenvolvimento de uma pedagogia visual é fundamental como desencadeadora de práticas educativas com crianças surdas, seja o(a) professor(a) ouvinte ou surdo(a) (CAMPELLO, 2007), embora saibamos que a presença de professoras surdas, que entendem radicalmente as potencialidades dos(as) alunos(as) surdos(as), facilita o desenvolvimento de processos pedagógicos mais engajados culturalmente. De acordo com Romário e Dorziat (2016, p. 65):

\begin{abstract}
A defesa pela observância desse critério - o professor ser Surdo ou a professora ser Surda -, assenta-se no fato de esse/a compreender melhor a importância e as formas de uso de recursos visuais no trabalho com crianças Surdas. Esse entendimento parte da convicção de que há uma facilitação na relação quando a mesma experiência identitária - visual - é partilhada nos processos escolares. Desse modo, há possibilidade de desenvolverem um melhor trabalho pedagógico-visual, com base na sua própria experiência identitária e escolar.
\end{abstract}

Segundo Skliar (2013), os Estudos Surdos almejam uma pedagogia própria das pessoas surdas, visto que, por meio desta, suas diferenças passam a ser reconhecidas e valorizadas: língua, identidades, arte, cultura e modo de ser e enxergar o mundo.

Desse modo, as professoras surdas, pautadas nas reais dificuldades de seus (suas) alunos (as), são as mais propícias a utilizarem os artefatos culturais surdos como princípio metodológico.

A significação da língua em suas vidas pode ser adensada não só pelo uso da língua em si, mas pelo conteúdo dos conhecimentos 
veiculados. Quanto mais sentido eles (conhecimentos) fizerem, mais imersão na cultura surda e mais possibilidade de sua apropriação e de construção de identidades empoderadas.

O discurso da professora Priscila sustenta o nosso argumento, quando diz:

Eu sou professora formada, gosto de ensinar, gosto de fazer materiais, metodologias diferenciadas próprias parasurd@s, euamo.Amo@surd@s,amoensiná-l@s.Para@surd@sas metodologias são diferentes sim. Eu mostro imagens, eu mostro a árvore e faço os sinais, com essa metodologia fica fácil. Quando el@svêema palavra em português,el@snão entendem.Quando el@svêem a árvore, o passarinho, eles entendem, a metodologia é diferente, é visual. (Professora Priscila)

A construção de uma pedagogia voltada para o mundo das pessoas surdas - a Pedagogia Surda - pode se constituir por discursos e práticas educacionais com capacidade de ressignificar processos educativos até então calcados numa cultura majoritária, sem impactos sobre as pessoas surdas. É uma "[...] pedagogia que tem a diferença surda como sustentáculo no processo educativo" (ROMÁRIO, 2018, p. 143), representando um movimento não só pedagógico, mas político, porque, ao construir uma pedagogia para as diferenças, possibilita a apropriação intelectual pelo próprio grupo de pessoas surdas, de modo a que ele delineie seus próprios caminhos, inclusive os educacionais.

\subsection{Desenvolvimento linguístico}

A situação a seguir põe à mostra a ênfase sobre o desenvolvimento linguístico existente no AEE, quando há uma professora surda responsável:

\begin{tabular}{|l|}
\hline \multicolumn{1}{|c|}{ SITUAÇÃO 2} \\
\hline \multicolumn{1}{|c|}{ Professora Paula } \\
\hline A professora Paula nos apresentou a um de seus alunos. Logo, ele perguntou: "Eles \\
falam?", e continua: "em casa, eu falo" [oralizo]. A docente corrige o aluno, afirman- \\
do: "na sua casa você oraliza, mas aqui na sala você tem de falar em Libras". Ela ain- \\
da acrescenta: "aqui somos todos iguais", apontando para a outra aluna, sua colega \\
surda que não oralizava.
\end{tabular}

Fonte: Dado colhido pelos/as autores/as.

Essa situação apresenta marcas da influência majoritária de famílias ouvintes na escolha da comunicação das crianças surdas e como a professora Paula se coloca em relação à sua língua. A 
docente corrige o aluno surdo, enfatizando a necessidade da utilização da língua de sinais, contrariando uma perspectiva ouvintista, que incentiva a supremacia da cultura ouvinte em detrimento da surda. O ouvintismo, em analogia aos processos colonizadores, representa a superioridade do mundo ouvinte, no qual a oralização é necessária às pessoas surdas, a fim de que elas, supostamente, possam se enquadrar aos padrões sociais e integrar-se a essa cultura dita superior (cultura oral). Goldfeld (2002, p. 34) afirma:

O Oralismo percebe a surdez como uma deficiência que deve ser minimizada pela estimulação auditiva. Essa estimulação possibilitaria a aprendizagem da língua portuguesa e levaria a criança surda a integrar-se na comunidade ouvinte e desenvolver uma personalidade como a de um ouvinte. Ou seja, o objetivo do Oralismo é fazer uma reabilitação da criança surda em direção a normalidade, a não surdez.

A professora Paula vai de encontro a essa perspectiva ouvintista: ela se comunicava exclusivamente por meio da Libras e defendia essa língua. Na escola, mesmo sem as pessoas dominarem a Libras, ela fazia questão de se comunicar apenas por meio dela, evitando estratégias que muitas pessoas surdas utilizam para driblarem a barreira linguística, como fazer leitura labial, escrever mensagem em papel, usar aplicativo de mensagens etc.

A professora surda buscava valorizar e utilizar sua língua em todos os momentos. Esta característica carrega em si um valor identitário que a torna modelo para seus pares: professora surda que utiliza a Libras e defende os valores, as crenças, os costumes e outros artefatos de sua cultura. Ela resiste, defendendo a cultura surda, mesmo diante de uma escola recheada de valores que tentam manter a hegemonia da língua oral; embora seja preciso reconhecer que, hodiernamente, haja uma abertura para a língua de sinais, considerando o seu papel de recurso metodológico-linguístico.

Ao solicitar que seu aluno se comunique por meio da Libras dentro da SRM, a professora surda não desrespeita a escolha da família em oralizar o filho, mas o incentiva a aprender por meio de sua língua natural. Ademais, é preciso ressaltar que o seu espaço de atuação (o AEE) é propício para tal, seguindo inclusive as recomendações do MEC. (DAMÁZIO, 2007)

Sobre a importância da língua de sinais, Strobel (2013, p. 53) assegura: 
A língua de sinais é uma das principais marcas da identidade de um povo surdo, pois é uma das peculiaridades da cultura surda, é uma forma de comunicação que capta as experiências visuais dos sujeitos surdos, e que vai levar o surdo a transmitir e proporcionar-lhe a aquisição de conhecimento universal.

A interação por meio da Libras entre a professora surda e seus alunos (pares surdos) permite que sejam construídas as bases para que eles se reconheçam como sujeitos pertencentes a uma cultura, a uma comunidade linguística. Este pertencimento é o ponto inicial para que desenvolvam uma identidade ligada à cultura surda, que irá se construindo e reconstruindo ao longo do tempo.

Na opinião da professora Priscila, o foco do trabalho com vistas à inclusão social é via ensino de Libras:

Eu acho muito importante ensinar Libras, porque eles precisam aprender Libras porque no futuro vão trabalhar... Precisam se comunicar... Com a família... Ensinar Libras é muito importante! Esseéofoco! É importante!@surd@s precisam de Libras (Professora Priscila).

A língua de sinais é a maior representante da cultura surda. Segundo Dorziat (2013, p. 29-30), "é a língua de sinais que dará condições de os surdos tornarem-se seres humanos na sua plenitude, através da apropriação dos conceitos científicos, disponíveis na educação formal". A língua de sinais, compreendida como mais que um simples instrumento metodológico, permite que as pessoas surdas aprendam os conteúdos escolares em sintonia com a vivência de valores, crenças e costumes próprios do mundo surdo.

Além impulsionarem uma prática escolar que enxergue as diferenças humanas e poderem usufruir da sua própria cultura dentro da escola, o uso da Libras pelas pessoas surdas contribui para a desestabilização de currículos homogêneos e práticas colonialistas.

É importante ressaltar isso, haja vista que o que se observou, historicamente, foi um movimento contrário. Foram muitas as interferências da cultura majoritária ouvinte na educação de pessoas surdas, como um padrão de ser humano. Essa visão única seria a mais adequada para se desenvolver estratégias de intervenção com todas as pessoas.

No caso das pessoas surdas, os discursos científicos exclusivamente clínicos e sobre processos linguísticos cristalizados refletiram negativamente sobre suas vidas. Em decorrência disso, 
elas encontram diversas dificuldades nos processos educacionais, sendo levadas a fracassarem no percurso escolar e, por conseguinte, ficando excluídas permanentemente da vida acadêmica.

Por isso, quando as professoras surdas em tela apresentam uma identidade politizada, elas contribuem para a apropriação dos(as) alunos(as) de artefatos culturais surdos que terão impactos positivos sobre a assimilação de conhecimentos e, sobretudo, sobre o processo de construção da cidadania. É a partir dessa dinâmica culturalmente engajada que seus(suas) alunos(as) podem ver possibilidades de gozar de plenos direitos sociais, como o de reivindicarem condições adequadas de escolarização - sobretudo quanto ao uso da língua de sinais - e o de se inserirem no mercado de trabalho em postos variados.

Além disso, a simples presença dessas professoras em posições hierarquicamente superiores, rompendo com as barreiras impostas pela cultura excludente, os(as) alunos(as) surdos(as) são impulsionados (as) a acreditar nas possibilidades de crescimento profissional.

Para essas professoras, a aprendizagem da língua portuguesa escrita pode alavancar processos mais contundentes de inserção social, sendo uma de suas preocupações pedagógicas:

\begin{tabular}{|l|}
\hline \multicolumn{1}{|c|}{ SITUAÇÃO 3} \\
\hline \multicolumn{1}{|c|}{ Professora Perla } \\
\hline O tema trabalhado era "FAMíLIA". Perla perguntou a um de seus alunos como se \\
escrevia a palavra FAMÍLIA. A professora começou a fazer os sinais dos membros da \\
família: PAI, MÃE, TIO, FILHO, IRMÃO... Depois, pediu que ele repetisse, soletrando \\
em Libras cada um. O menino soletrou corretamente cada nome, mas se atrapalhou \\
ao fazer os sinais de FILHO, por conta do LH, e de TIO, por conta do T (confundiu \\
com F). Ela mostrou a diferença de sinais masculinos e femininos, explicando que, \\
na escrita em Libras, usava-se @ para representar homem e mulher e, em português, \\
diferenciava-se com A ou O.
\end{tabular}

Fonte: Dado colhido pelos/as autores/as.

Vimos na situação supracitada que a professora surda além de ensinar a Libras no AEE, atribuição prevista para ela nas recomendações do MEC, ela também ensinava a Língua Portuguesa, atribuição designada a uma pessoa ouvinte formada preferencialmente em Língua Portuguesa. (DAMÁZIO, 2007) Isso demonstra que a professora sabe da importância do português escrito para seus(suas) alunos(as) e da necessidade de desenvolver um trabalho comparativo com sua língua natural.

Tendo as pessoas surdas adquirido a sua primeira língua (língua de sinais), é recomendável que sejam empreendidos esforços 
para a aquisição da Língua Portuguesa escrita, a fim de que seja proporcionada um maior espectro de autonomia para esses sujeitos.

O bilinguismo prevê essa possibilidade, entendendo que contextos diferentes requerem o uso de diferentes línguas. (QUADROS, 2012) No entanto, é indispensável que essa iniciativa não redunde em subtração de direitos das pessoas surdas, quanto a ter disponível, em todos os ambientes sociais, recursos humanos e(ou) materias para uso da língua de sinais.

O risco de a língua de sinais perder espaço pode ser uma das razões para atitudes de resistência de alguns grupos surdos quanto à aprendizagem da língua portuguesa. Outro motivo justaposto a esse é a dificuldade de apropriação de uma língua (língua portuguesa) com características fonéticas, próprias de uma população áudio-oral.

Quadros (2012) assegura, no entanto, haver possibilidade de um espaço de negociação, sem que as pessoas surdas percam o lugar político de reivindicação de direitos por uma sociedade que as inclua enquanto pessoas pertencentes a uma cultura surda. Isto quer dizer que o bilinguismo pode ser ressignificado: ambas as línguas serem apropriadas, sem que isso signifique submissão colonialista, mas instrumento de empoderamento surdo.

Dessa forma, as pessoas surdas podem encarar a aprendizagem e o uso da Língua Portuguesa escrita como forma de favorecer a sua inserção social, sem que esta língua desconsidere ou prevaleça sobre a sua língua natural.

Na situação analisada, cabe destacar a observância da professora em relação aos aspectos culturais das diferentes línguas. Ela mostra a seu aluno como se marca o gênero na Libras e na Língua Portuguesa. Além de pôr em prática o bilinguismo, a professora faz questão de mostrar como cada língua se comporta em termos normativos.

Diante disso, não obstante a Libras ser o artafato linguístico próprio da cultura surda, a Língua Portuguesa escrita unida à Língua de Sinais caracteriza o bilinguismo para as pessoas surdas, uma vez que, neste lugar de negociação entre as duas línguas, as pessoas surdas adquirem mais condições de se relacionarem numa sociedade heterogênea. O que se espera da educação, então, é que ela incorpore o bilinguismo, visando a construção de uma educação mais inclusiva e democrática. 
Na próxima situação, podemos verificar uma prática que ilustra a importância de trabalhar a literatura nos processos educacionais de alunos(as) surdos(as):

\begin{tabular}{|c|}
\hline SITUAÇÃO 4 \\
\hline Professora Paula \\
\hline $\begin{array}{l}\text { Durante a apresentação da história Chapéuzinho Vermelho em Libras, uma das alu- } \\
\text { nas de Paula estranhou um determinado sinal, demonstrando que não o conhecia. } \\
\text { Paula explicou a ela que, no estado de São Paulo (local onde, segundo ela, o vídeo } \\
\text { foi produzido), os sinais eram diferentes dos sinais paraibanos, esclarecendo que a } \\
\text { Libras pode variar de acordo com cada região do Brasil. Logo na sequência, em um } \\
\text { dos momentos do vídeo, a intérprete fez a datilologia de BOLO, e a aluna, de ime- } \\
\text { diato, fez o sinal correspondente. No decorrer da história de Chapéuzinho Vermelho, } \\
\text { quando o lobo aparece, Paula perguntou qual era o sinal de LOBO. A menina fez o } \\
\text { mesmo corretamente e a professora deu a resposta afirmativa, fazendo uma pequena } \\
\text { complementação sobre a história. }\end{array}$ \\
\hline
\end{tabular}

Fonte: Dado colhido pelos/as autores/as.

Nesta situação, quando a professora surda trabalhava um material produzido pelo Instituto Nacional de Educação de Surdos (INES), intitulado "Histórias Infantis em Língua de Sinais" da Coleção Educação de Surdos, observamos que ela traz um elemento importante para a educação das pessoas surdas: a literatura vista sob o ângulo da língua de sinais. Esse aspecto metodológico permite o trabalho com conceitos e variações linguísticas, além da compreensão de situações contextualizadas.

A aluna surda, ao perceber sinais diferentes, expôs seu conhecimento acerca de sua língua, assim como teve a oportunidade de obter uma breve explanação sobre as variações linguísticas regionais, materializadas por diferentes sinais em Libras que variam de uma região para a outra.

Pedagogicamente, a contextualização feita pela professora Paula, para que a aluna compreendesse, foi uma demonstração de como é importante a atenção da professora às sutilezas da língua de sinais, que podem levar a aluna a não compreender um sinal por ser diferente em outra região brasileira. Por isso, é indispensável a utilização de uma metodologia em que o contexto seja a base para a aprendizagem. A literatura se presta muito bem para isso: o significado dos símbolos é visto num contexto mais amplo e complexo, com sentido linguístico-cultural para a criança surda.

A didática utilizada pela professora Paula permite-lhe iniciar o trabalho com os textos literários de forma mais significativa, representando e transmitindo conhecimentos. Isso é especialmente importante em se tratando dos anos iniciais de escolarização, nos 
quais as crianças surdas necessitam de um contato mais efetivo com a sua língua, por meio de recursos adequados à faixa etária.

O uso da literatura nos processos educacionais possibilita a inserção significativa das crianças surdas no mundo da fantasia, de forma dinâmica e divertida, além de ser um dispositivo de inserção futura mais engajada à literatura propriamente surda.

Durante a entrevista, a professora Paula aponta que acha importante a literatura nos processos educacionais:

Eu acho importante imagens, trabalhar imagens em cartolinas, $o$ alfabeto é importante, vídeos, histórias, fábulas, imagens em Libras no notebook, atividades em Libras [...] (Professora Paula).

Paula tem consciência da importância de trazer a literatura por meio da língua de sinais e imagens para os processos educacionais, proporcionando às crianças surdas a oportunidade de vivenciarem dinâmicas próprias do mundo infantil, de forma plena e contextualizada.

\section{Considerações finais}

O desenvolvimento desta pesquisa foi importante, porque permitiu evidenciar aspectos importantes de emergência da cultura surda nos processos educacionais, por meio da relação entre professoras surdas e alunos(as) surdos(as), contribuindo para a construção de referenciais para a formação docente em Pedagogia Surda.

Partindo do princípio de que a cultura surda é uma produção histórico-social e plural, constituída fundamentalmente pela experiência visual, selecionamos docentes surdas como sujeitos desta pesquisa.

A partir desse protagonismo - docentes e discentes surdos (as) -, selecionamos situações pedagógicas que mostraram maior suscetibilidade de fazer emergir os aspectos da cultura surda, tornando os processos de ensino e aprendizagem mais significativos para as crianças surdas.

O "livro sensorial", produzido por uma das professoras surdas, foi um exemplo disso. Ao explorar a experiência visual das pessoas surdas, a professora demonstra, com propriedade, sua capacidade de produzir materiais próprios à cultura surda e sua preocupação com as singularidades de seus pares culturais, sustentando uma prática que expõe a relevância da Pedagogia Surda. 
Essa iniciativa coloca a importância de se aliar a língua de sinais aos aspectos pedagógicos nos processos educacionais das pessoas surdas. A língua de sinais, nesse contexto, assume seu real valor, ao incorporar, para além do aspecto de tradução entre línguas, a estreita relação com processos educacionais significativos para os(as) alunos(as) surdos(as), explorando sua potencialidade visual. Mesmo inseridas em escolas com procedimentos hegemônicos em torno da língua oral, as prioridades das professoras parecem transpor o ensino meramente técnico para contribuir com processos que fortaleçam também a construção das identidades surdas.

Essa preocupação não exclui o uso de procedimentos vistos, à princípio, como pragmáticos. Sem desconsiderar a língua natural (L1) das pessoas surdas, critério para as elaborações cognitivas, as professoras surdas enfatizam também a importância da aprendizagem da língua portuguesa escrita, uma vez que ela favorece a inserção social dessas pessoas na realidade social em que estão inseridas.

Quando as professoras surdas utilizam a Libras para desenvolver a literatura, elas possibilitam as crianças adentrarem no mundo infantil da fantasia e contribuem para tornar as ideias sobre o entorno mais contextualizadas e significativas.

A realidade analisada apresentou, portanto, possibilidades de construção de processos pedagógicos que unam a educação e a cultura surda, desde que os artefatos desta sejam considerados. Podemos dizer que a semente desse processo está sendo plantada na escola regular por meio do trabalho de professoras(es) surdas(os), que buscam considerar as diferenças linguístico-pedagógicas das crianças surdas.

Assim, chamamos a atenção para a necessidade de suporte e adensamento de processos educacionais dessa natureza, em que há esforço para trazer a diferença para o centro do processo. Esse é o caminho para a escola se tornar, realmente, mais inclusiva.

\section{Incentive to deaf culture in educational processes: visual experience and linguistic development in focus}

\footnotetext{
Abstract: This paper analyzes the pedagogical practices of deaf teachers who work with deaf students in regular public schools in João Pessoa, Paraíba, Brazil. Based on the Deaf Studies, we show the cultural productions that emerge from their visual experiences, materialized in the deaflanguage and identities. To that end, observations and interviews were made with three teachers who performed the Specialized Educational Service, in the Multi-
} 
functional Resource Classes, space where we consider that the interactions between deaf people (teacher-student), occur more directly. From the pedagogical and narrative situations of deaf teachers, we highlight elements such as: visual experience and linguistic development.The analyzes showed that it is possible to construct pedagogical processes that combine education and deaf culture, as long as the artifacts of the deaf culture are considered and there is support for the densification of educational processes that make an effort to bring the difference to the center of the process. This is the way for the school to become, indeed, more inclusive.

Keywords: Education. Education of the deaf. Inclusive education.

\title{
Incentivo a la cultura sorda en los procesos educacionales: experiencia visual y desarrollo lingüístico en foco
}

\begin{abstract}
Resumen: Este artículo analiza prácticas pedagógicas de profesoras sordas que actúan con estudiantes sordos en escuelas públicas regulares de João Pessoa, Paraíba, Brasil. Con base en los Estudios Sordos, evidenciamos las producciones culturales que emergen de sus experiencias visuales, materializadas en la lengua e identidades sordas. Para ello, hicimos observaciones y entrevistas con tres profesoras sordas que desarrollaban la Asistencia Educacional Especializada, en las Salas de Recursos Multifuncionales, espacio donde consideramos que las interacciones entre personas sordas (profesora-estudiante) ocurrían más directamente. De las situaciones pedagógicas y narrativas de las profesoras sordas, destacamos elementos, como: la experiencia visual y el desarrollo lingüístico. Las análisis mostraron que es posible la construcción de procesos pedagógicos que unan la educación y la cultura sorda, siempre que los artefactos de ésta sean considerados y haya soporte para el adensamiento de procesos educativos que tengan esfuerzo para traer la diferencia al centro del proceso. Este es el camino para que la escuela se vuelva realmente más inclusiva.
\end{abstract}

Palabras clave: Educación. La educación de los sordos. Educación inclusiva.

\section{Referências}

BARDIN, Laurence. Análise de conteúdo. Tradução Luís Antero Reto e Augusto Pinheiro. São Paulo: Edições 70, 2011.

CAMPELlO, Ana Regina e Souza. Pedagogia Visual/Sinal na Educação dos Surdos In: QUADROS, Ronice M.; PERLIN, Gladis (org.). Estudos Surdos II. Petrópolis, RJ: Arara Azul, 2007. p. 100-131.

CRUZ NETO, Otávio. O trabalho de campo como descoberta e criação. In: MINAYO, Maria Cecília de Souza (org.). Pesquisa Social: teoria, método e criatividade. 16. ed. Petrópolis, RJ: Vozes, 2002. p. 51-66.

DAMÁZIO, Mirlene Ferreira Macedo. Atendimento educacional especializado: pessoa com surdez. Brasília: DF: Ministério da Educação, 2007. 
DORZIAT, Ana. Bilinguismo e surdez: para além de uma visão linguística e metodológica. In: SKLIAR, Carlos (org.)Atualidade da educação bilíngue para surdos: processos e projetos pedagógicos. Porto Alegre: Editora Mediação, 2013. p. 29-30.

GESUELI, Zilda Maria. Língua(gem)e identidade: a surdez em questão. Educação e Sociedade, Campinas, v. 27, n. 94, p. 277-292, jan./abr. 2006.

GOLDFELD, Márcia. A criança surda: linguagem e cognição numa perspectiva sócio-interacionista. 2. ed. São Paulo: Plexus Editora, 2002.

GRAY, David E. Pesquisa de mundo real. 2. ed. Porto Alegre: Penso, 2012. MINAYO, Maria Cecília de Souza. Ciência, técnica e arte: o desafio da pesquisa social In: MINAYO, Maria Cecília de Souza. (org.). Pesquisa social: teoria, método e criatividade. Petrópolis: Vozes, 2001. p. 9-30.

PERLIN, Gladis; MIRANDA, Wilson. Surdos: o narrar e a política. Ponto de Vista, Florianópolis, n. 5, p. 217-226, 2003.

QUADROS, Ronice Müller de. Ideias para ensinar português para alunos surdos. Brasília, DF: Ministério da Educação, 2006.

QUADROS, Ronice Müller de. O "BI" em bilinguismo na educação de surdos. In: LODI, Ana Claudia Balieiro; MÉLO, Ana Dorziat Barbosa de; FERNANDES, Eulália (org.). Letramento, bilinguismo e educação de surdos. Porto Alegre: Mediação, 2012. p. 187-200.

RICHARDSON, Roberto Jarry. Pesquisa social: métodos e técnicas. São Paulo: Atlas, 1999.

ROMÁRIO, Lucas. Pedagogia surda: cultura, diferença e construção de identidades. Curitiba: EDITORA CRV, 2018.

ROMÁRIO, Lucas; DORZIAT, Ana. Considerações sobre a pedagogia visual e sua importância para a educação de pessoas surdas. Revista Cocar, Belém, v. 10, p. 52-72, 2016.

SILVA, Tomaz Tadeu da. Documentos de identidade:uma introdução às teorias do currículo. 3. ed., 2. reimp. Belo Horizonte: Autêntica, 2011.

SKLIAR, Carlos. Estudos Surdos em Educação: problematizando anormalidade. In: SKLIAR, Carlos. (org.). A surdez: um olhar sobre as diferenças. 6. ed. Porto Alegre: Mediação, 2013.

STROBEL, Karin. As imagens do outro sobre a cultura surda. 3. ed. rev. Florianópolis: Ed. da UFSC, 2013.

TRIVIÑOS, Augusto Nibaldo Silva. Introdução à pesquisa em ciências sociais: a pesquisa qualitativa em educação. São Paulo: Atlas, 1987.

Submetido em : $30 / 11 / 2018$

Aprovado em : 14/03/2019 